$2013 / 8$

\title{
Analysing and Understanding the Construction of Vernacular Buildings at the National Technical University of Athens
}

\author{
Constantine A. Caradimas, National Technical University of Athens
}

\begin{abstract}
This paper presents a course organized by the Department of Architectural Technology of the School of Architecture of the National Technical University of Athens (NTUA) that focuses on the systematic architecture survey and structural analysis of traditional settlements and buildings. The course is an "elective" study course in the $8^{\text {th }}$ semester of the undergraduate studies that is run continuously with great success and feedback from students since the academic year 1975-76.
\end{abstract}

Keywords - Architectural conservation, architectural education, construction of historic buildings.

\section{The Course at the School of Architecture at NTUA}

The course presented here is organized by the Department of Architectural Technology of the School of Architecture of the National Technical University of Athens (NTUA). It focuses on the systematic architecture survey and structural analysis of traditional settlements and buildings. For our Department this course is considered a milestone of high educational merit and cognitive value, since it gives the students both the method and the knowledge for the fundamental understanding and evaluation of vernacular buildings, their characteristics and construction, the behaviour, pathology and weathering of materials and finally the structural analysis of traditional construction. Furthermore, an equally important objective of the course is to raise awareness among students and local communities on issues of protection of the Architectural Heritage, as well as the enhancement of future architects with knowledge and tools in order to be able to deal successfully with similar projects in the future.
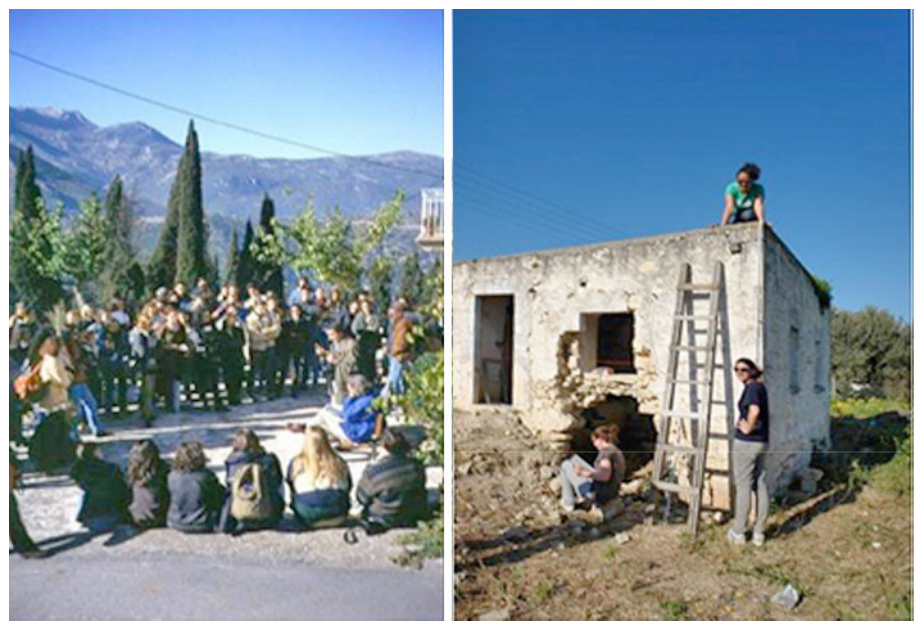

The course is an "elective" study course in the $8^{\text {th }}$ semester of the undergraduate studies, when the students have already obtained the necessary maturity needed in order to combine the theoretical general knowledge acquired with more specialized approaches and suggestions of implementation. In this way, the students involved already have quite a number of educational semesters with projects in architectural design, architectural technology, city planning and at least one semester in the field of analysing and evaluating vernacular settlements and measuring historic buildings.

Furthermore, most students definitely have a specific interest in understanding vernacular buildings, traditional construction and conservation techniques. Actually, in many cases this course tends to be the stepping stone in educating architectural students in the field of renovation of old buildings, this being a possible topic for postgraduate studies at NTUA or elsewhere, or a possible potential in their professional carrier. This is mainly because it is the only course at the undergraduate program of the School that deals, to such an extent, with all these specialized matters.

The course has been taught continuously with great success and feedback from students since the academic year 1975-76. During all these years the course is being enriched and evolved scientifically and multidisciplinary. It experiments and explores possibilities provided by new technologies, new materials, design programs and simulators, framed with new colleagues and, therefore, it has been remaining for many years at the forefront of architectural education and technology.

In the beginning, the course started for the first time in Greece with such a scientific approach, on restoration and reuse studies of traditional and vernacular buildings and modern monuments in
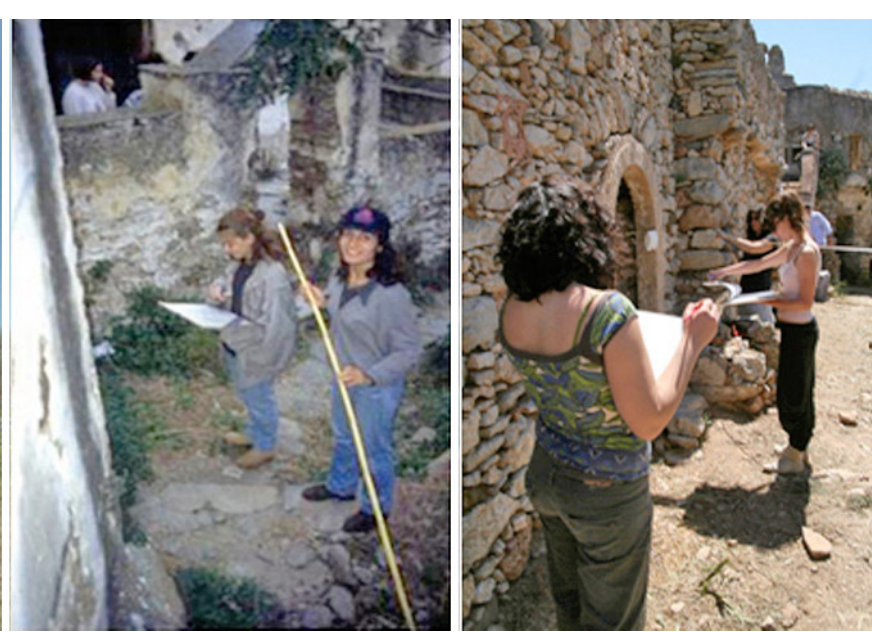

Fig. 1. Students working in situ. 


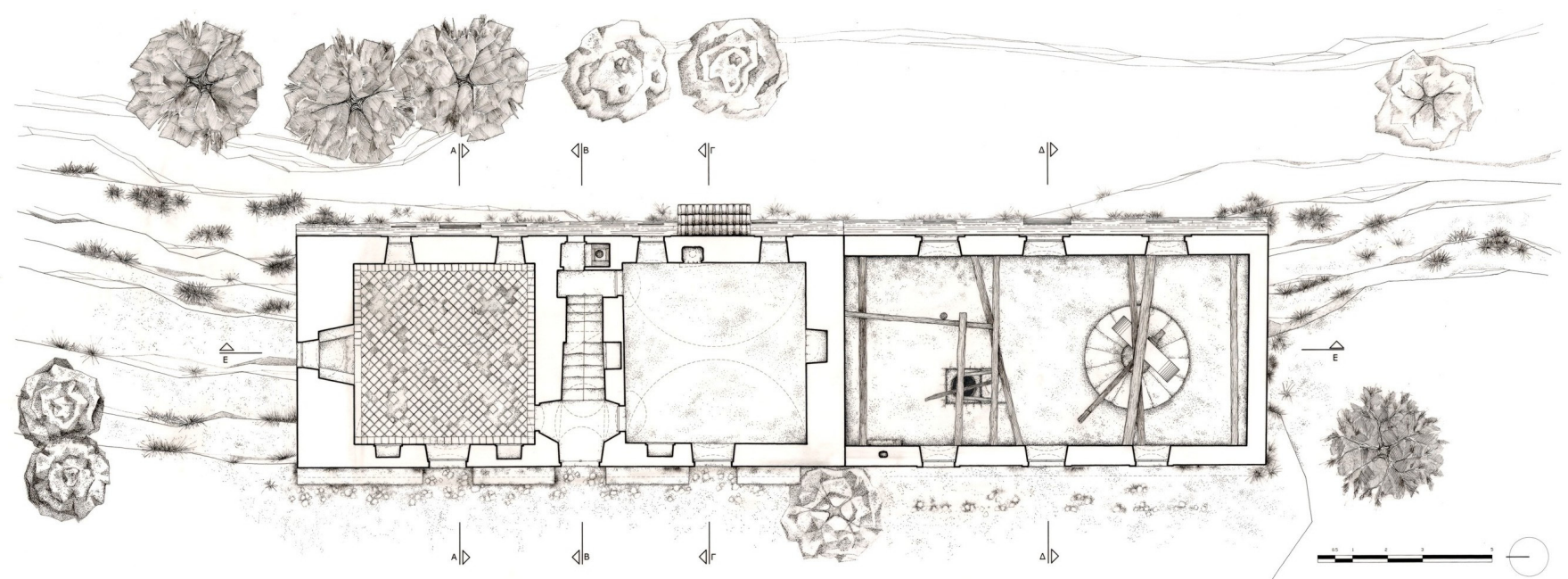

Fig. 2. Academic Year 2007-8. The "Askitario" Monastery Complex in the north of Corfu. First Floor Plan.
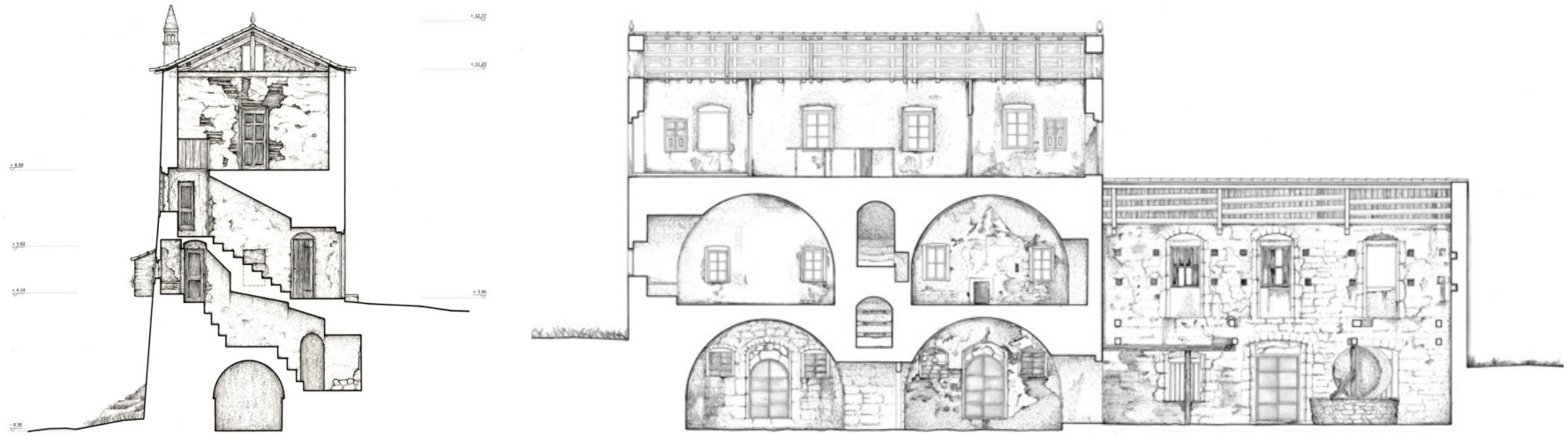

Fig. 3. Academic Year 2007-8. The "Askitario" Monastery Complex in the north of Corfu. Sections.

general, with an emphasis on construction issues. It was almost an experimental lesson, since the scientific environment on related topics - both in Greece and in Europe - was at a primary stage.

Buildings constructed using the known, traditional building methods and local materials like stone, mud bricks, bricks, wood, etc. were featured as the "traditional" ones. The primal objective was the need to acquire basic knowledge that would allow graduates of the School to deal with the reuse of existing buildings. These buildings, after a long period of depreciation and dispute, had then begun to be assessed again as architectural values. Already in this area there was a corresponding activity of architects worldwide, culminating in the European Architectural Heritage Year in 1975. Very quickly it became clear also in Greece that the architectural value of buildings as well as the need to reuse and maintain a large building stock that was discredited and left in devastation was very important for historical, cultural, and financial reasons.

Under these circumstances, the undergraduate course started at the Department of Architectural Technology of NTUA, with systematic survey of the building structure and analysis of features of traditional settlements and buildings. From the very beginning, it became clear that the substantial knowledge of the structural systems and their pathology was a prerequisite for designing proposals of re-use, maintenance and rehabilitation, compatible with historic buildings.
Furthermore, the involvement of the academic staff with relevant research programs, seminars, conferences, the interdisciplinary collaborations, the participation in international scientific networks and workshops in Greece and abroad, as well as the architectural practice facilitated the continuous evolutionary process of the course.

\section{Description OF THE COURSE}

The projects to be presented in the article are the outcome of a common effort of a great number of colleagues - both Architects and Civil Engineers - from our Department during all these 37 years. The method that was followed both for the analysis and the adaptive reuse study was that of the construction and the structural analysis of the building. The possible differences in the approach are not of great importance and are viewed more as the scientific and research value of this field.

The course tries to cover as many aspects as possible with an aim:

- to make a thorough study of the existing situation of the buildings by means of measured drawings, building fabric survey, construction analysis etc.;

- to examine the methods of technology and processes of traditional structures and the use of the corresponding materials; 


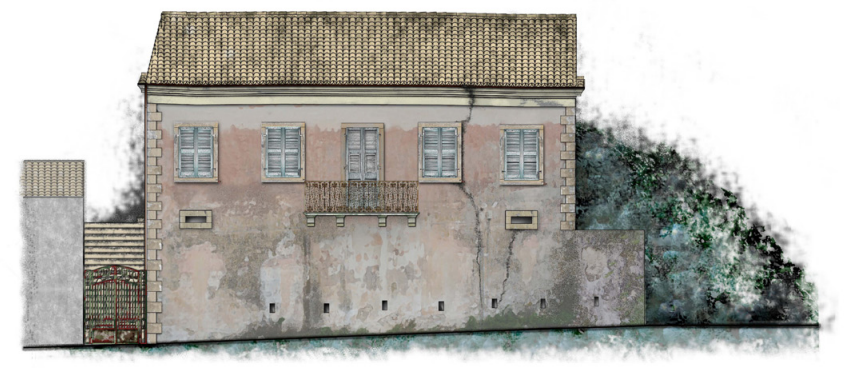

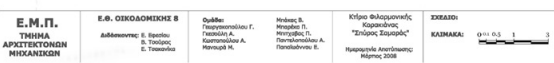

Fig. 4. Academic Year 2007-8. The "Philharmonic Orchestra" building, in Corfu. South Elevation.
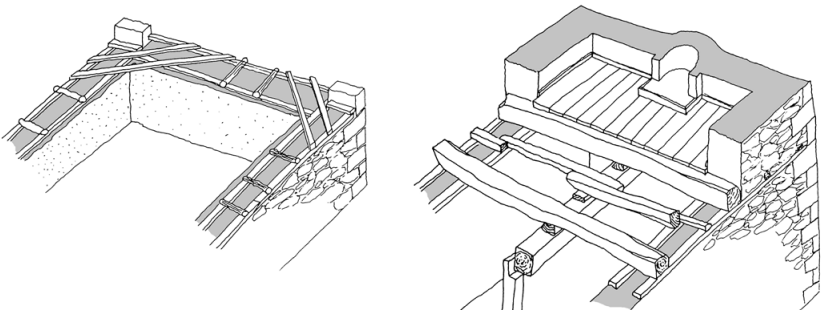

Fig. 5. Academic Year 2009-10. Traditional Houses in Trikala, Prefecture of Korinth. Construction details.

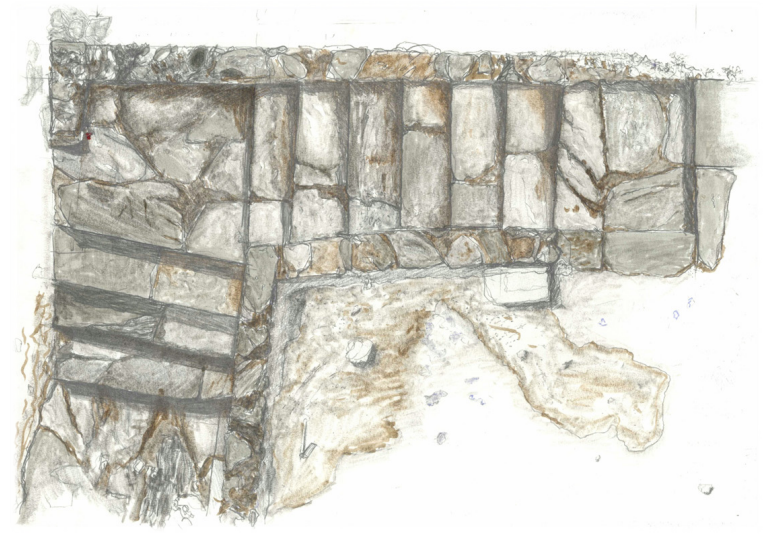

Fig. 6. Academic Year 2008-9. Traditional Houses in Kythira. Detail of a staircase.
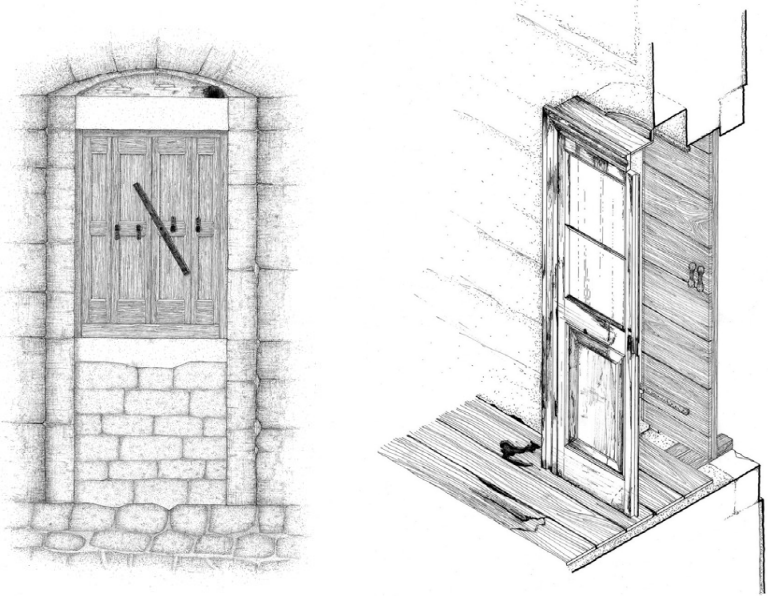

Fig. 7. Academic Year 2007-8. The "Askitario" Monastery Complex in the north of Corfu. Details of doors and windows.

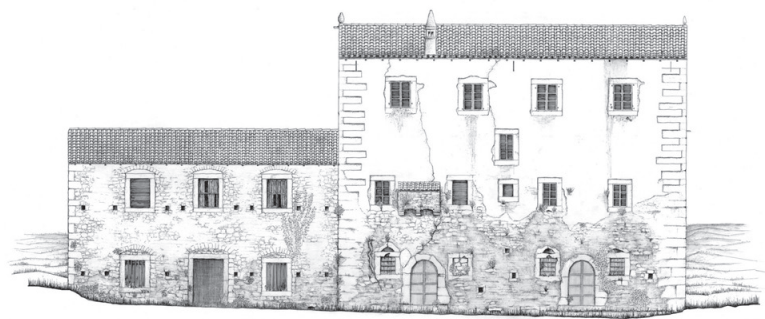

Fig. 8. Academic Year 2007-8. The "Askitario" Monastery Complex in the north of Corfu. Elevation showing defects and vegetation.

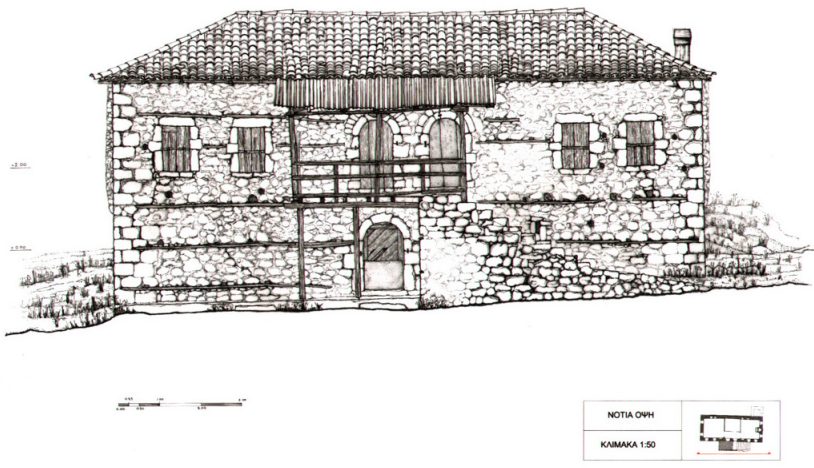

Fig. 9. Academic Year 2009-10. Traditional houses in the Municipality of Trikala, Prefecture of Korinth. Elevation showing defects.

- to understand the structural and construction system of the building by creating a model showing the construction system as a whole;

- to identify and explain the defects - damage to the structures, their pathology and vulnerability, their weathering both in climatic conditions and in natural strains and the causes of their decay;

- to study the proposals for the remedial action to be implemented;

- to undertake an adaptive reuse study of the buildings involved.

For the purposes of the course, a specific settlement in Greecewith an adequate number of traditional buildings of more or less united character - is selected every year. In the past three years, this was done in conjunction with the local authorities of the area selected. The involvement of local authorities had great advantages, since the selected buildings were also judged by architects of the local community that had quite good knowledge of the area, the buildings and their potential. The selection is mainly based on criteria of quality or special historical value of the buildings and in some cases on the local need to have thorough measured drawings and fabric survey of the building for possible future needs by the local community. During all these 37 years of the existence of the course, we have visited a great number of places all over Greece; for example: Mesagros Aegina (1999, 2011 \& 2012), Trikala Corinth (2010), Kato Chora Milopotamos Kythera (2009), Corfu (2008), Sotiras Mani (2004), Lagadia Gortynias, (2003), Thisbe Boeotia (2002), Viniani Evritania (2001), Syros (2000), Dimitsana Arcadia (1998), Monasteria Tinos (1997), Sklavia and Campos Chios (1996), Mesa Gonia Santorini (1994), Vathia Mani (1993), Andros (1992), Lefkada (1991), Tampakika Amfissa (1990) etc. 


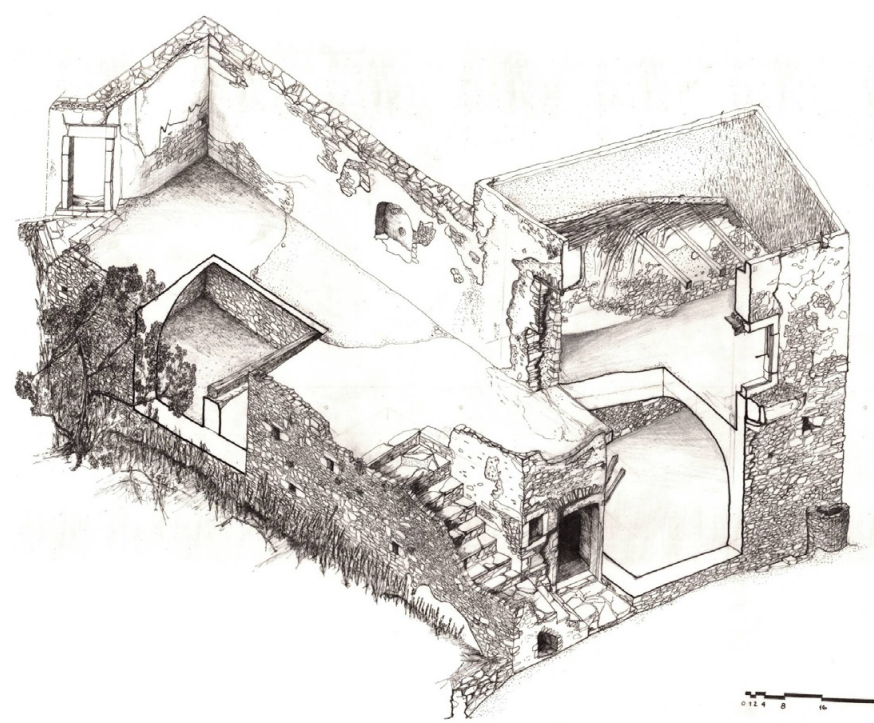

Fig. 10. Academic Year 2008-9. Traditional houses in Kythira. Construction models.

Students - an approximate number of 45 - are separated into 3 groups and visit the area under the supervision of responsible academic staff, usually 2 per group. The visit usually takes place after a series of introductory lectures lasting 3 to 4 weeks. The lectures give a theoretical background in most fields of conservation work involved, such as methodology of conducting measured drawings, building fabric, construction analysis methods, traditional building technology, pathology, vulnerability and main damage causes, conservation techniques, etc.

The site visit usually lasts 3 days, where all the data and information are collected in the form of drawings sketches, photographs etc. All this is processed at the University in Athens with systematic evaluation of all the material collected in situ by both the students and the academic staff following the analytical diagram of work according to the characteristics of each project (Figure 1).

The analysis of the building, the building fabric survey, the material analysis, and the construction model of the building take into consideration all the characteristics of traditional architecture, as stated in the beginning of this paper, to enable the students to understand the blending of all these elements in the creation of traditional architecture. The analysis follows a general methodology in order to cover as many aspects as possible and to fulfil the scope of the course, but at the same time the special characteristics of each building examined are analysed and explained in the general context of special identity of the area.

When the semester is concluded, students present their study projects in the form of drawings, reports; for instance:

- drawings of the existing situation of the building; Plans (Figure 2), Sections (Figure 3), Elevations (Figure 4), 3Ds and details (Figures 5-7);

- drawings analysing the buildings defects, their causes, the necessary remedial action with the possible proposed reinforcement and the conservation techniques involved (Figures 8 and 9);

- drawings of the structural and construction system model of the building (Figures 10 and 11);

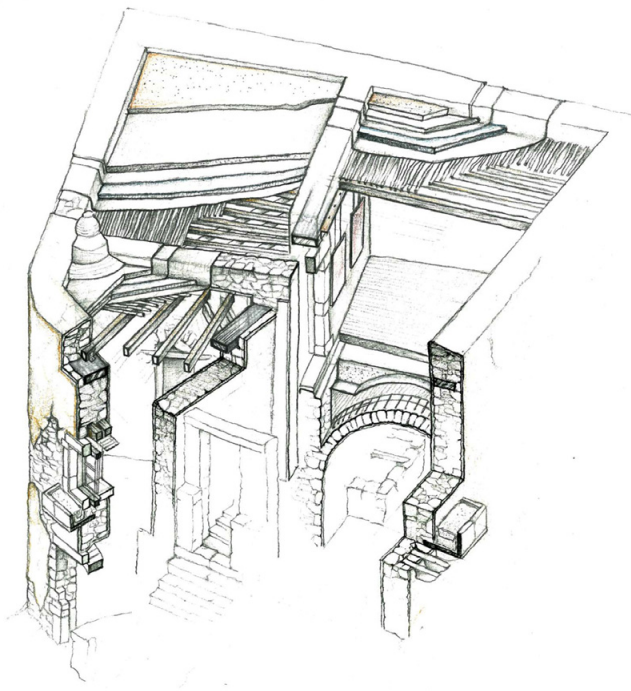

- drawings of the adaptive new use of the building and/or the new extensions involved;

- analysis in the form of a written paper of the building fabric, the problems and defects found, the causes of the defects and the decay found, the remedial action that should be taken and the necessary work to be done to adapt this building to a new use.

After the completion of the academic procedure, a very interesting experiment was made in the last years. An exhibition was created in the area, where the project was undertaken. The exhibition took place in collaboration with the local authorities of the area, with great support and interest from both the authorities and the inhabitants. Therefore, each group of students prepared a series of panels with the main points of their projects, especially designed for the exhibition purposes. Up to now two exhibitions like that have already been conducted, the first one has been organised in Corfu in conjunction with the Prefecture of Corfu and the second one in Kythira, in conjunction with the Municipality of Kythira, while the third exhibition in the municipality of Trikala, in the Prefecture of Korinth, is projected in the near future.

The exhibition in Corfu took place at the main building of the Prefecture of Corfu. The opening was combined with a conference organized by the Architects Association of Corfu and the Corfu Branch of the Technical Chamber of Greece under the title "Is the Past Defining the Future?" The exhibition had great publicity and was finally kept as a permanent exhibition in the common areas of the main building of the Prefecture of Corfu.

The exhibition at Kythira took place at the Kytherian Society in Chora Kythiron. It was named under the title "The Architectural Character of Kythira", "The Recognition of the Architectural Identity of Settlements and Buildings of Kythira through the Eyes of the Students of the National Technical University of Athens" and was the first architectural exhibition that ever took place on this isolated island in the south of Greece.

The scope of these exhibitions is to sensitise the local societies with the values of vernacular buildings and the merits of their building systems. We consider that the universities of each country 

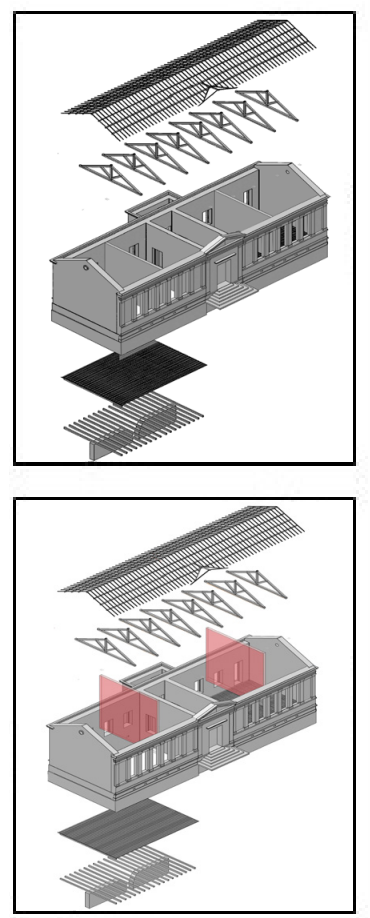
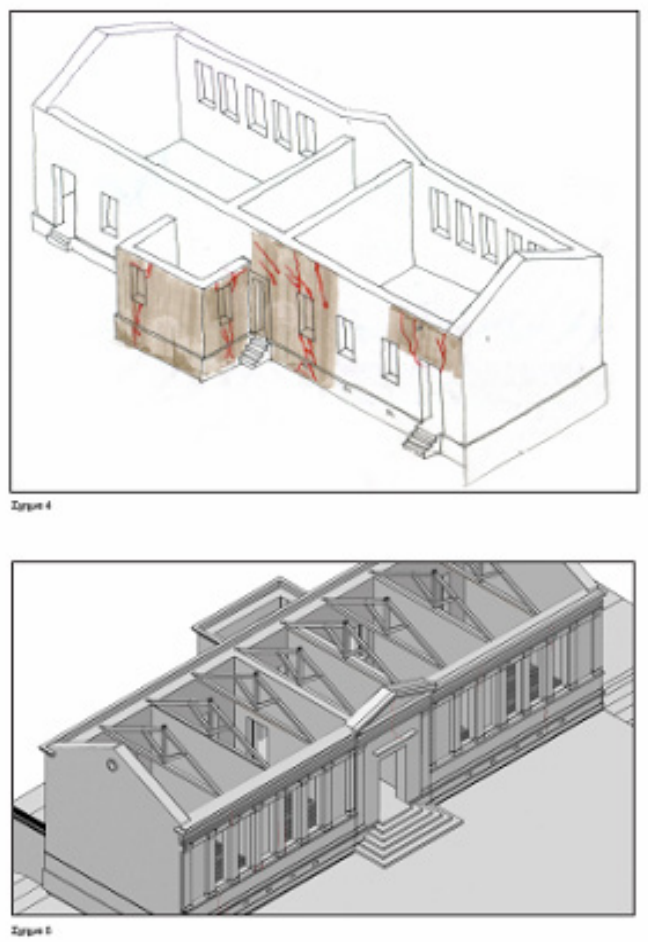

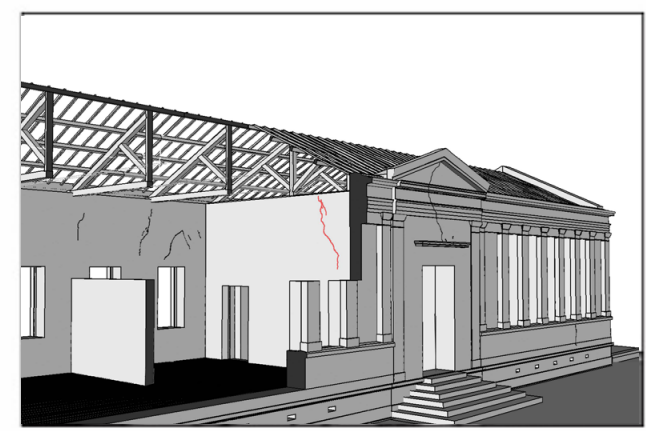

Donst

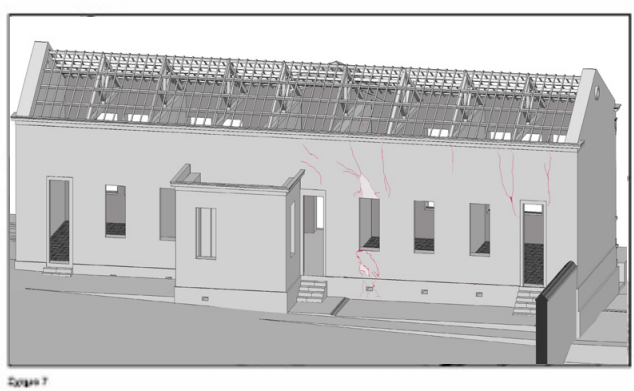

Fig. 11. Academic Year 2007-8. Primary School in Mastoratika. Paxoi Island. Isometric construction models

should work towards this goal, educate local communities with exhibitions, lectures and collaborations in order to enable the protection of the architectural heritage of each place.

\section{Conclusions}

The analysis of traditional buildings is a useful tool for the architectural teacher to make his students understand building construction in a different approach from the usual one followed at the University Studio. In this procedure students study the existing situation of buildings by means of measured drawings, building fabric survey, construction analysis and try to understand technology methods and processes of traditional structures, the use of corresponding materials in order to create a structural and construction system of the building as a whole. This procedure also enables students to identify and explain the defects damage to the structures, their pathology and vulnerability, their weathering and the causes of their decay in order to study the proposals for the remedial action to be implemented. Thus, students obtain knowledge and methodological tools to deal with traditional buildings and existing structures, and especially students are provided with an opportunity to appreciate the values, to understand the importance of the architectural heritage of their place, and to act as teachers educating the public for the same scope.

Teachers who have participated or continue to participate in the course presented here are the Architects: + Dimitris Biris, Panagiotis Touliatos, Vangelis Evangelinos, Nick Kalogeras, Francis Goulielmos, Constantinos Mylonas, Spyros Raftopoulos, Miltos Tzitzas, George Makris, Elias Zacharopoulos, Vassilis Tsouras, Helen Alexandrou, Panagiotis Vassilatos, Irene Efesiou \& Costas Caradimas, and the Civil Engineers: Sanias Kirpotin and Eleftheria Tsakanika.
The examples presented in this paper are taken from different student projects from the past three years of study and actually follow the analytical diagram of their work as stated by the Teaching Fellows of the Department of Architectural Technology at the School of Architecture of the National Technical University of Athens. All drawings presented in this paper are taken from the archives of the Laboratory of Architectural Technology of the School of Architecture at the NTUA.

\section{REFERENCES}

1. Caradimas, C. A. Understanding the unity of Architecture by analyzing Vernacular Settlements. EAAE-ENHSA Architectural Design \& Construction Education experimentation towards integration Genoa, Italy, 11-13 June 2009 [C. Spyridonidis and M. Voyatzaki, ed.]. Thessaloniki, 2009, p. 539-548.

2. Caradimas, C. A., Efesiou, I. Educating Students and Community by Analyzing Vernacular Settlements and Buildings. EAAE-ENHSA Educating Architects towards Innovative Architecture, Istanbul, 17-19 June 2010 [C. Spyridonidis and M. Voyatzaki, ed.]. Thessaloniki, 2010, p. 219-232.

3. Caradimas, C. A. Understanding the Unity of building construction by analyzing traditional Architecture. 10 $0^{\text {th }}$ International Detail Design in Architecture Conference, Istanbul, 27-28 October 2011 [ M. Cem Altun and S. Emmitt, ed.]. Instanbul: Istanbul Technical University, 2011, p. 99-106.

4. Caradimas, C. A, Tsouras, V. The traditional construction in architectural education. 11th Panhellenic Architectural Conference, Athens, 17-20 March 2011. Athens 1011, p. 36.

5. Doumanis, C., Oliver, P. Settlements in Greece. Publication Architecture in Greece, Athens, 1974.

6. Goulielmos, F., Efesiou I., Tsakanika, E. Historical Building Systems : Education - Research - Application. 11th Panhellenic Architectural Conference, Athens, 17-20 March 2011. Athens, 2011, p. 36-37. 
7. Arnaoutoglou, C. Skyros Greek Traditional Architecture. Athens: Melissa, 1984. $40 \mathrm{p}$

8. Kondaratos, S. Architecture and tradition. Athens: As. Kondaratos Th. Kastaniotis, 1985, 90 p.

9. Rapoport, A. Anonymous Architecture and cultural factors. Publication Architecture in Greece, Athens, 1976.

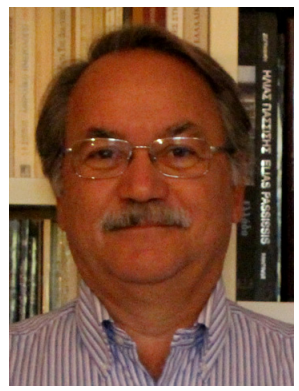

Constantine A. Caradimas (Athens, 1954).

Graduated from the School of Architecture at the

National Technical University of Athens (NTUA) (1977).

Postgraduate Studies in Architectural Conservation

of Historic Buildings and Vernacular Settlements at the Heriot-Watt University \& Edinburgh College of Art (1979).

Teaching Associate at the National Technical University of Athens, at the Department of Architectural Technology (1994-2000).

Assistant Professor (Law 407/80) at the Department of Building Design \& Construction, at the School of Architecture of the Democritus University of Thrace (2002-2007).

Assistant Professor at the Department of Architectural Technology of the School

of Architecture at the National Technical University of Athens. (2007 - onwards).

\section{Contact Data}

Constantine A. Caradimas

Architect, Assistant Professor at NTUA

National Technical University of Athens

School of Architecture

Department of Architectural Technology

42 Patission Str., 10682 Athens, Greece

Tel: +30 210772 3933, fax: + 302107723898 ,

E-mail: ccara@tee.gr \& ccara@arch.ntua.gr 